\title{
Isolation of Stigmast- 4 -ENE-3-One and Gamma- Sitosterol from the Aerieal Part of Synedrella Nodiflora Linn (Asteracae)
}

\author{
M.B. Yakubu ${ }^{1 *}$, J. Yusuf ${ }^{2}$ and J.B. Gambo ${ }^{2}$ \\ Department of Applied Science, Kaduna Polytechnic, Kaduna, Nigeria
}

\begin{abstract}
Pulverized aerial plant material (100 g) of Synedella nodiflora Linn was exhaustively extracted with petroleum spirit, chloroform, ethyl acetate and methanol, the extracts was concentrated in-vacuo using rotary evaporator at $40^{\circ} \mathrm{C}$. The ethyl acetate extract was subjected to column chromatography analysis to yield various fractions which were combined based on their thin layer chromatography analysis to give SEA. This was further purified by the preparatory thin layer chromatography (PTLC) to give SEA-1. The structure of the isolated compounds was established by IR and GC-MS spectroscopic analysis and by direct comparison of the data obtained with those reported in literature to be stigmast- 4 -ene-3-one and gamma-sitosterol. The compounds are reported for the first time from this plant. General phytochemical screening of the aerial parts of Synedrella nodiflora revealed the presence of flavonoids, alkaloids, tannins, steroids, glycoside and cardiac glycoside.
\end{abstract}

Key words: Phytochemical screening, synedrella nodiflora, gamma-sitosterol and stigmast-4-ene-3-one.

\section{Introduction}

Synedrella nodiflora Linn (Geartn) belongs to the family of Asteraceae. A straggling annual herb that grows nearly $2 \mathrm{~m}$ high a Fibrous woody root stock, a native of tropical America and now dispersed pantropically, which occurs throughout the region in waste places. It is an annual plant which grows in many parts of Nigeria and Africa in general (Burkill, 1985). The leaf infusion is drunk as laxative and leaf sap is used for treating dental infections in the Congo. (Bouquet, 1969) A paste of the leaf is also used in topical embrocation for oedema and rheumatism in Ivory Coast (Kerharo and Bouquet, 1950). In Ghanaian traditional medicine, the aqueous extract of the whole plant is taken for the treatment of epilepsy. The plant is used extensively in Nigeria for cardiac troubles, Wounds healing and to stop bleeding (Idu and Onyibe, 2000). In Malaysia and Indonesia, the plant is used for the treatment of headaches, earaches, stomachaches and in embrocation for rheumatism. (Burkill, 1985) Alkaloids, sequiterpense lactones, tannins, flavoniod, steroids and terpeniod are the most abundant principles of this genus (Burkill, 1985). The compounds present in the genus represent several bioactivities ranging from anti-inflammatory, antioxidant, analgesic, astringent, antimicrobial among a host of many others [Sharma et al, 2000]

Collection, identification and preparation of plant material

\section{Materials And Methods}

The aerial parts of the plants were collected from Samaru- Zaria; Kaduna State in August 2010.

It was identified by Mallam Umar Galla of the Herbarium of Biological Sciences Department, Faculty of Science, Ahmadu Bello University Zaria, Nigeria. A specimen was deposited in the herbarium with voucher number 359; the plant material was pulverized by the use of a wooden mortar and pestle and then stored in polythene bag until needed for use.

\section{Extraction and Isolation}

The classical procedure for obtaining organic constituents from dried plant was used (Harbone and Turner, 1985). Air-dried and pulverized plant material (100 g) was extracted successively using the soxhlet extractor with petroleum ether $60-80^{\circ} \mathrm{C}$, chloroform, ethyl acetate and methanol in order of their polarities. The solvents were collected and concentrated in-vacuo using a rotary evaporator at $40^{\circ} \mathrm{C}$.

\section{Thin layer chromatography}

This was used to determine the number of chemical components in the ethyl acetate fraction and the most suitable mobile phase for good resolution. The plant extract was dissolved in minimum amount of methanol, spotted at the base of the plate and developed using petroleum ether, chloroform, ethyl acetate and methanol in different ratios. The resulting chromatograms, after air-drying was viewed under short ultraviolet wave length of $(\mathbf{2 5 4} \mathbf{~ n m})$ and long visible wavelength of $(\mathbf{3 6 6} \mathbf{~ n m})$. Finally, a ratio of 7:3 of petroleum ether and diethyl ether was found to be the most suitable mobile phase that provided an excellent resolution. This culminated in the selection of this mixture as the best solvent system for column chromatography. 


\section{Column chromatography of ethyl acetate extract}

The separation of the ethyl acetate extract into different chemical components was carried out in two stages using column chromatographic technique with silica gel as the stationary phase.

A glass column of $100 \mathrm{~cm}$ long and internal diameter of $3 \mathrm{~cm}$ was used. $2.0 \mathrm{~g}$ of silica gel $(60-200$ mesh) was activated in an oven at $110^{\circ} \mathrm{C}$ for 1 hour. It was allowed to cool at room temperature in a desiccator. Slurry of silica gel was made with the solvent system and packed into the column. The system was preconditioned by passing the solvent continuously for 30 minutes. $2.0 \mathrm{~g}$ of the crude extract of ethyl acetate extract was dissolved in minimum volume of the solvent system and mixed with $3.0 \mathrm{~g}$ of silica gel. This was then loaded on to the top of the column and after, draining the solvent to the level of the gel bed, $2.0 \mathrm{~g}$ silica gel was added to protect the surface of the column when eluting the column. Fractions were collected using conical flask at a flow rate of $50 \mathrm{~cm}^{3}$ per hour until the issuing eluent was clear of extract. All the fractions collected were concentrated in- vacuo using rotary evaporator, spotted on TLC plates and developed with the same solvent system. Similar fractions were pooled together and allowed to evaporate at room temperature under laboratory condition. This evaporated fractions were further ran on a smaller column and the whole process above was repeated. Similar fractions were further combined together and finally subjected to preparative thin layer chromatography (PTLC) technique for further purification; the purified sample obtained in form of white needle-like crystals was labelled SEA-1, it was found to be a mixture of stigmast- 4- ene-3-one and gammasitosterol (figure 1).

\section{Spectroscopic analysis:}

The fractions separated were analyzed using GC- MS in methanol as solvent. The results obtained were compared with in -built main library data.

Figure 1: This shows stigmast-4-ene-3-one and gamma-sitosterol
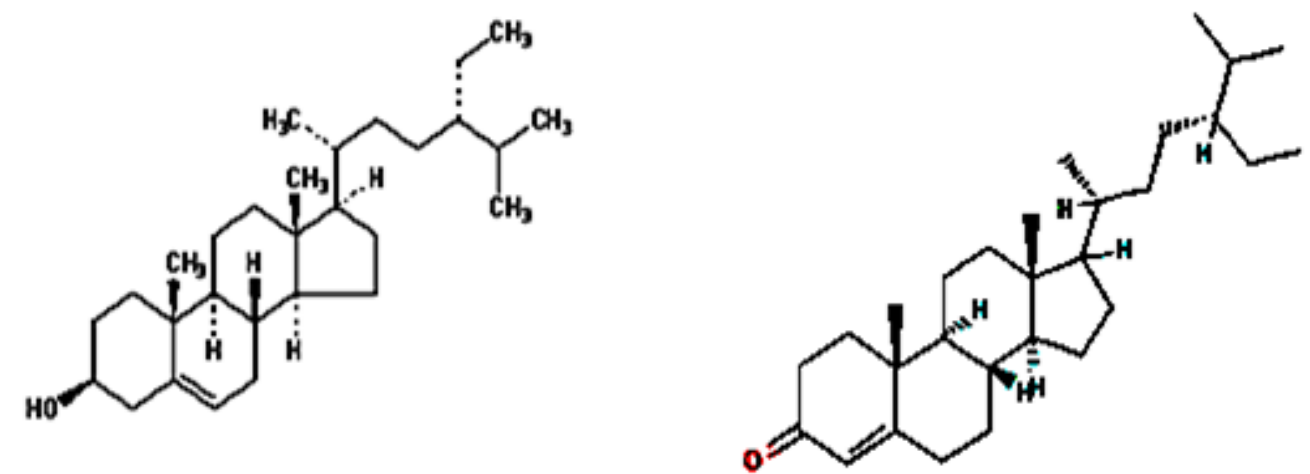

Gamma-sitosterol $\mathrm{C}_{29} \mathrm{H}_{50} \mathrm{O}$ Mol. Wt: 414.71

\section{Results And Discussion}

The infrared spectrum IR Figure 2 of the isolated component has the following characteristic absorptions in $\left(\mathrm{cm}^{-1}\right) .3414 .29$ typical absorption of $\mathrm{C}-\mathrm{H}$ stretch in alcohols and phenols, 2865.26 absorption characteristic of $\mathrm{C}-\mathrm{H}$ stretch of methylene groups, 1720.96 typical of $\mathrm{C}=\mathrm{O}$ stretching vibration of carbonyl group, 1359 typical of $\mathrm{CO}-\mathrm{CH}_{3}$ (Willaims and Flemmings, 1980).

GC- MS: The mass spectrum Figure 3 of peak at retention time 37.494 minutes and area of $45.505 \%$ from the Gas Chromatogram has base peak at $\mathrm{M}^{+}=412$ and molecular ion MZ 695, other peaks were given at $\mathrm{M} / \mathrm{Z}=43$ which correspond to $\mathrm{C}_{3} \mathrm{H}_{7}{ }^{+}$, and the peak at M/Z 397 was due to the loss of a methyl group, the peak at M/Z 370 was due the loss of $-\mathrm{COCH}_{2}$. Other peaks at M/Z 355, M/Z 257 and M/Z 229 are losses that were due to alkyl groups, $\mathrm{C}_{8} \mathrm{H}_{17}$ and $\mathrm{C}_{10} \mathrm{H}_{21}$ from the peak at M/Z 370. The peaks at 313, 271 and 327 were also losses of $\mathrm{C}_{7} \mathrm{H}_{15}$, $\mathrm{C}_{10} \mathrm{H}_{21}$ and $\mathrm{C}_{6} \mathrm{H}_{13}$ respectively. A library search on the data base came back with a $99 \%$ match for stigmast-4ene-3-one. (Jain and Bari2010). 
Figure 2: This figure shows the infrared spectra of SEA-1

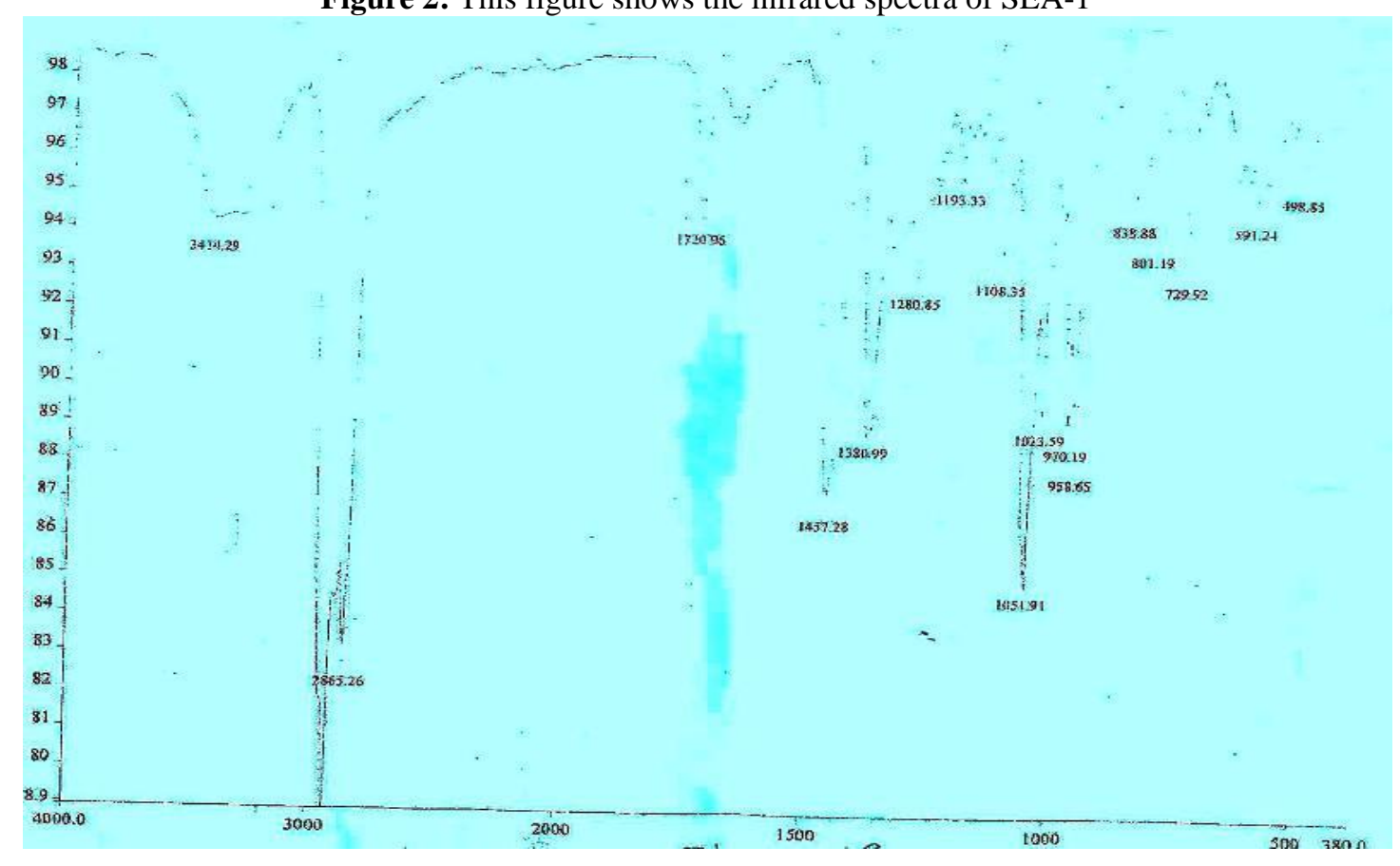

Figure 3: This figure shows GC-MS for stigmast-4-ene-3-one

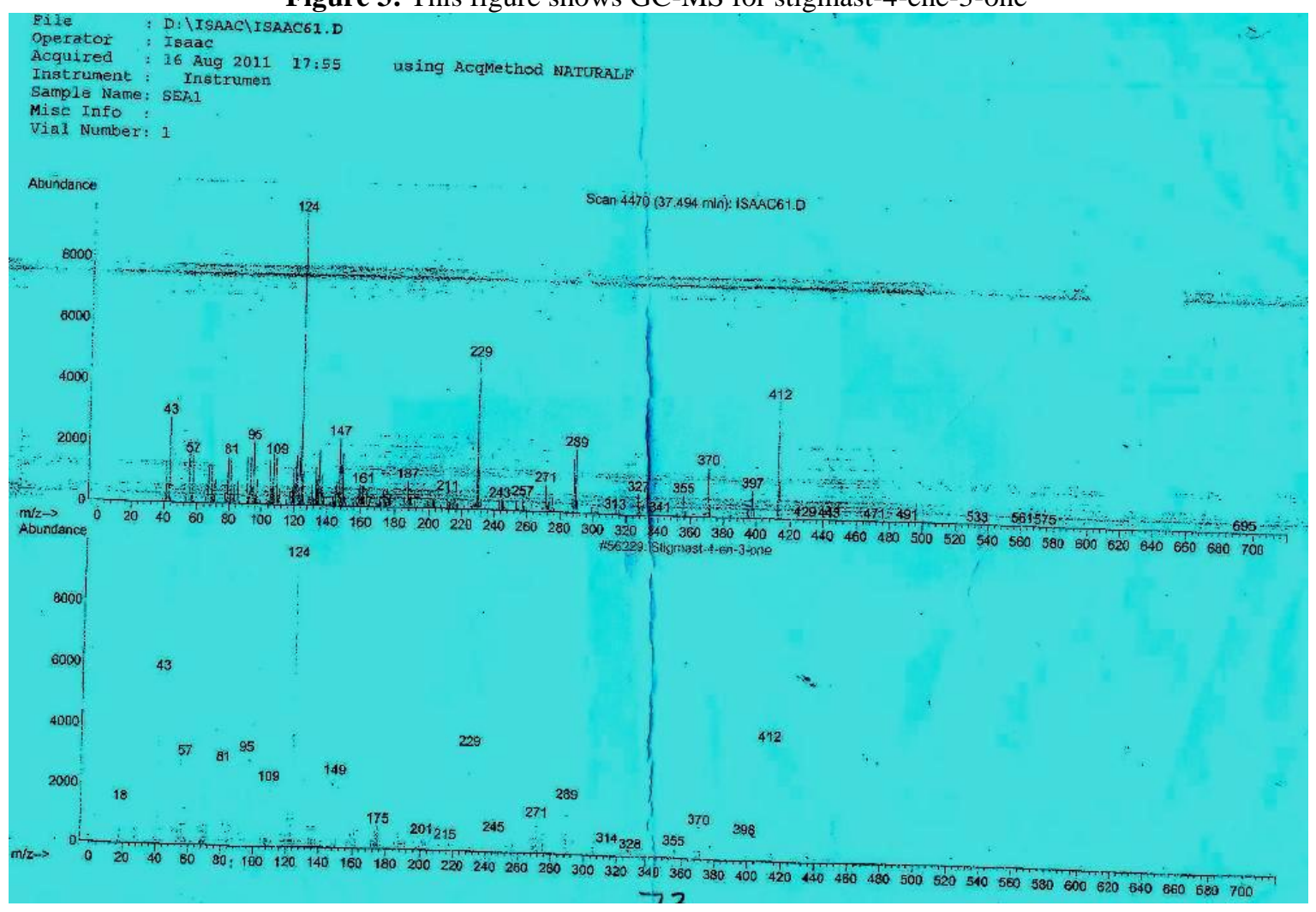

The mass spectrum Figure 4 of peak at retention time 27.005 minutes and area $31.222 \%$ from the Gas Chromatogram has a base peak at $\mathrm{M}^{+} 414$ and molecular ion $\mathrm{MZ}=655$. The peak at $\mathrm{M} / \mathrm{Z} 273$ corresponds to the loss of $\mathrm{C}_{10} \mathrm{H}_{21}$. The dehydration of the fragment at $\mathrm{M} / \mathrm{Z} 273$ would further yield $M / Z 255$. Fragment $M / Z$ 231 was due to the loss of $\mathrm{C}_{13} \mathrm{H}_{27}$, More fragments are at $\mathrm{M} / \mathrm{Z} 303\left(\mathrm{M}^{+}-111\right)$ and $\mathrm{M} / \mathrm{Z} 329\left(\mathrm{M}^{+}-85\right)$, the peak at $\mathrm{M} / \mathrm{Z} 396$ is due to loss of a water molecule from the molecular ion $\left(\mathrm{M}^{+}-\mathrm{H}_{2} \mathrm{O}\right)$, the loss of $\mathrm{C}_{13} \mathrm{H}_{27}$ from M/Z 396 produces the peak at M/Z 213 this peak further fragmented via Retro Diels Alder (RDA) reaction to produces the peak at M/Z 159 and lastly the peak at M/Z 43 was due to $\mathrm{C}_{3} \mathrm{H}_{7}{ }^{+}$. A library search on the spectrum of this 
compound on the data base came back with $99 \%$ match for gamma-sitosterol. (Pretsch and Affolter, 2000), (Klause, 1962), (Grassell, 1973).

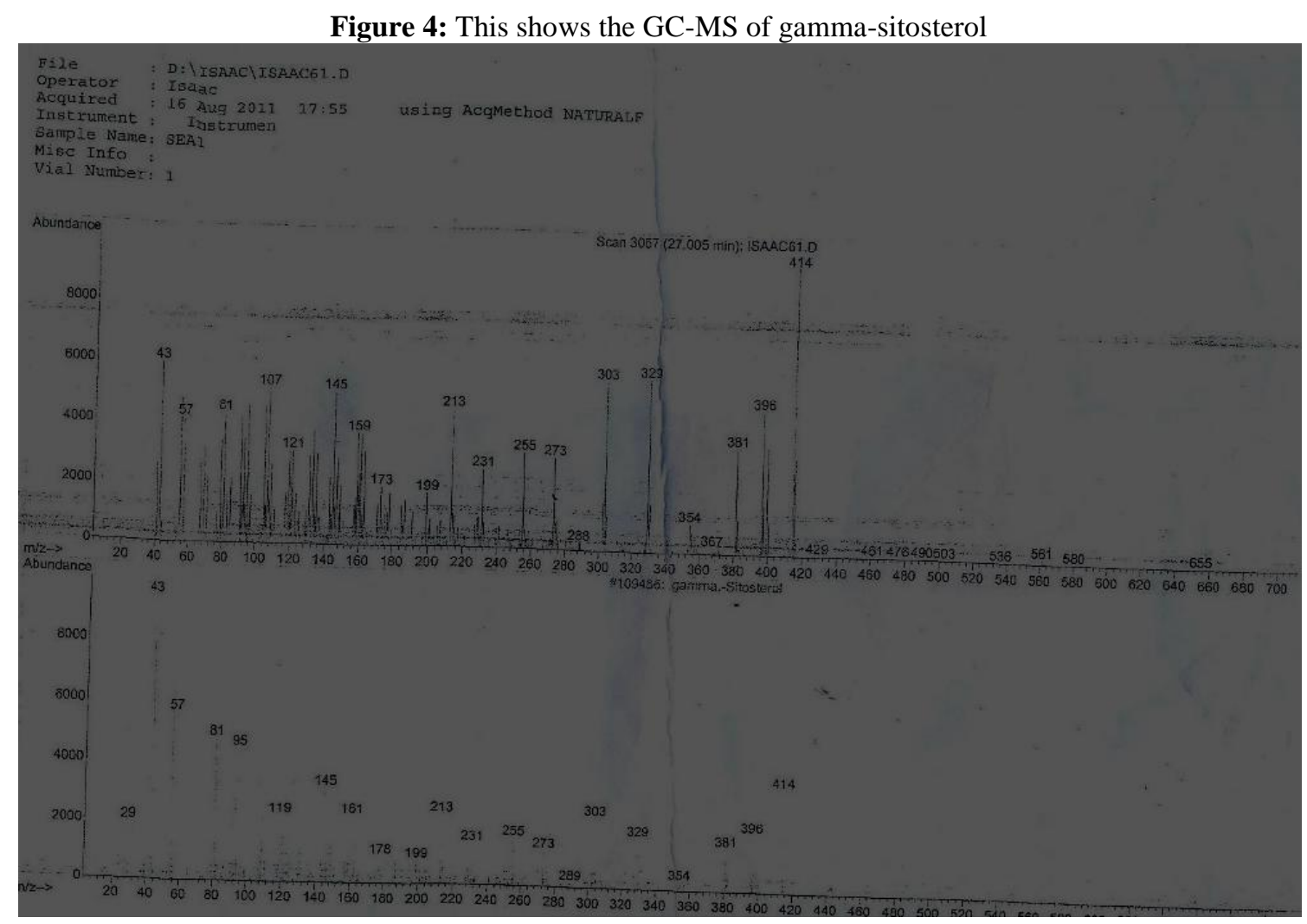

\section{Conclusion}

From the above findings stigmast-4-ene -3- one and gamma -sitosterol was isolated from the ethyl acetate extract of synedrella nodiflora Linn (Asteraceae) and their chemical structures confirmed.

\section{Acknowledgement}

Authors thank Professor Francis Oluwole Shode and Dr.Isaac Bello of Department of Chemistry, University of kwa- zulunatal, Durban, South Africa for helping in running the GC-MS and IR Spectroscopy of the sample. We also like to acknowledge the Chemistry Department, Ahmadu Bello University, Zaria, Nigeria for providing an enabling laboratory environment for this research work.

\section{Reference}

[1]. Burkhill H.M (1985), the useful plants of tropical West Africa, volume 1, pp.293 -295.

[2]. Bouquet,A.(1969). F'eticheurs et m’edecines traditionnelles du Congo (Brazzaville memoireO.R.S.T.O.M.

[3]. Grasselli, J.G. (1973) "CRC spectral Data and physical constant for organic compounds" CRC press. Cleveland. Ohio

[4]. Harborne,J.B. Turner.B,L (1984) Plant Chemosystematics, 7th ed. Academic Press, London,pp. 45-50

[5]. Idu, M and Onyibe, H.I (2000) Medicinal plants of Edo State, Nigeria. Research Journal of Medicinal plant, 1:32-41

[6]. Jain, P., and Bari, S., (2010). Stigmasterol and Campesterol from petroleum ether extract of woody stem of Wrightia tinctora, Asian journal of plant science, 163-167

[7]. Kerharo, J. and Bouquet, J. (1950). Plantes Medicinalis de la Cote d'Ivoire et Haute Volta, Paris. p.289

[8]. Klause Biemann (1962) "Mass spectrometry- organic chemical application" McGraw-Hill Book Co pp46-361 "Annual report on NMR spectroscopy" vol. 8 Acadamic press inc. London pp. 199-226

[9]. Pretsch, E.B. Affolter, (2000) A Structure determination of organic compounds table of spectra data. Springer- Verlag. Berlin Heidelberg. pp 71-150

[10]. Sharma R.A., Singh B., Singh D., Chandrawat P. (2000). Ethnomedicinal Pharmacological properties and chemistry of some medicinal plant of Boraginaceae in India. Journal of medicinal plants Research 3(13):1153-1175, 2008.

[11]. Willams, H.D., and Flemming. L.(1980). Spectroscopic Methods in Organic Chemistry, (3 ${ }^{\text {rd }}$ ed). MacGraw-Hill Book company (UK) Limited, pp 180-181. 